\title{
An ion-neutral model to investigate chemical ionization mass spectrome- try analysis of atmospheric molecules - application to a mixed reagent ion system for hydroperoxides and organic acids
}

Brian G. Heikes et al.

Correspondence to: Brian G. Heikes (bheikes@uri.edu)

The copyright of individual parts of the supplement might differ from the CC BY 4.0 License. 
S1. Notes on mechanism development and adjustment of kinetic rates to resolve pressure and humidity trends in $\mathrm{O}_{2}^{-}\left(\mathrm{H}_{2} \mathrm{O}_{2}\right), \mathrm{O}_{2}^{-}\left(\mathrm{CH}_{3} \mathrm{OOH}\right), \mathrm{O}_{2}^{-}\left(\mathrm{CO}_{2}\right)\left(\mathrm{H}_{2} \mathrm{O}_{2}\right), I^{-}(\mathrm{HFO})$ and $\mathrm{I}^{-}(\mathrm{HAC})$ sensitivities.

\section{S1.1 Base thermodynamic data for the $\mathrm{O}_{2}^{-}-\mathrm{O}_{2}-\mathrm{CO}_{2}-\mathrm{H}_{2} \mathrm{O}-$ hydroperoxide system.}

Formation enthalpy $\left(\Delta H_{f}^{o}\right)$, entropy $\left(\Delta S^{o}\right)$, and Gibb's formation energy $\left(\Delta G_{f}^{o}\right)$, data are published for some of the neutral, ion and ion-cluster species involved in the $\mathrm{O}_{2}^{-}-\mathrm{O}_{2}-\mathrm{CO}_{2}-\mathrm{H}_{2} \mathrm{O}-$ hydroperoxide system. Reaction enthalpy $\left(\Delta \mathrm{H}_{r}^{o}\right)$, entropy $\left(\Delta S_{r}^{o}\right)$, and Gibb's energy $\left(\Delta G_{r}^{o}\right)$ data are also available for some of the reactions involved in this system. These thermodynamic data are summarized in Table A5 and Table A6. The NIST Chemistry WebBook (Bartmess, 2016) was used extensively in this analysis as it provides summary information from primary sources. In cases for which multiple values are available and without a recommended value, we have indicated which primary data set we adopted. Additional formation and reaction energies were taken from ab initio calculations by Messer et al. (2000), Cappa and Elrod (2001), Goldsmith et al. (2012) and O'Sullivan et al. (2017). For ions and ion-cluster species and reactions, care must be exercised as to the notation used for the energy terms. Often, but not always, the ion and ion-neutral cluster species and reaction literature follows a negative sign convention with respect to the neutral species and neutral reaction literature. Here we have adopted a sign convention such that exothermic reactions have a negative reaction enthalpy and spontaneous reactions have a negative Gibb's reaction energy.

The following thermodynamic relationship is used to calculate energy terms which were not previously available from the primary literature or the NIST Chemistry WebBook,

$$
\Delta H_{r}^{o}-T_{o} \times \Delta S_{r}^{o}=\Delta G_{r}^{o}
$$

where $T_{o}=298.15 \mathrm{~K}, \Delta H_{r}^{o}$ is the stoichiometric sum of the formation enthalpies, $\Delta H_{f}^{o}$, of the products (j index) minus the stoichiometric sum of the formation enthalpies of the reactants (i index),

$$
\Delta H_{r}^{o}=\sum_{j}^{J} v_{j} H_{f, j}^{o}-\sum_{i}^{I} v_{i} H_{f, i}^{o},
$$

$\Delta S_{r}^{o}$ is the stoichiometric sum of the standard entropies, $S^{o}$, of the products minus the stoichiometric sum of the standard entropies of the reactants,

$$
\Delta S_{r}^{o}=\sum_{j}^{J} v_{j} S_{j}^{o}-\sum_{i}^{I} v_{i} S_{i}^{o},
$$

and $\Delta G_{r}^{o}$ is the stoichiometric sum of the Gibb's formation energies, $\Delta G_{f}^{o}$, of the products minus the stoichiometric sum of the Gibb's formation energies of the reactants,

$$
\Delta G_{r}^{o}=\sum_{j}^{J} v_{j} G_{f, j}^{o}-\sum_{i}^{I} v_{i} G_{f, i}^{o},
$$


where, $v$ represents the stoichiometric coefficient for a species in a reaction. Formation energies for a reactant or product species are calculated using published $\Delta H_{f}^{o}$ and $\Delta G_{f}^{o}$ for that species as the sole product and the reactants are taken to be in their standard state and form with $\Delta G_{f}^{o} \equiv 0$ and $\Delta H_{f}^{o} \equiv 0$. In the case of the ab initio calculations, the Gibb's energy at $298.15 \mathrm{~K}$ and $1013.25 \mathrm{hPa}, G^{o}$, is calculated for each reactant and product and $\Delta G_{r}^{o}$ is calculated by stoichiometrically summing the ab initio Gibb's energies (Ochterski, 2000) of the products and then subtracting the stoichiometric sum of the reactants:

$$
\Delta G_{r}^{o}=\sum_{j}^{J} v_{j} G_{j}^{o}-\sum_{i}^{I} v_{i} G_{i}^{o}=\sum_{j}^{J} v_{j} G_{f, j}^{o}-\sum_{i}^{I} v_{i} G_{f, i}^{o} .
$$

The formation and reaction energies so calculated in this work are underlined and bold-faced in the Tables A5 and A6.

Goldsmith et al. (2012) estimated formation enthalpies, entropies and Gibb's formation energies for $\mathrm{CH}_{3} \mathrm{OOH}$ and many other low molecular weight combustion related compounds. O'Sullivan et al. (2017) estimated Gibb's reaction energies at $298.15 \mathrm{~K}$ and $1013.25 \mathrm{hPa}$ for:

$$
\begin{array}{ll}
\mathrm{O}_{2}^{-}+\mathrm{CH}_{3} \mathrm{OOH} \rightleftharpoons \mathrm{O}_{2}^{-}\left(\mathrm{CH}_{3} \mathrm{OOH}\right) & \Delta G_{r}^{o}=-231 \mathrm{~kJ} \mathrm{~mol}^{-1} \\
\mathrm{O}_{2}^{-}\left(\mathrm{H}_{2} \mathrm{O}\right)+\mathrm{CH}_{3} \mathrm{OOH} \rightleftharpoons \mathrm{O}_{2}^{-}\left(\mathrm{CH}_{3} \mathrm{OOH}\right)+\mathrm{H}_{2} \mathrm{O} & \Delta G_{r}^{o}=-181 \mathrm{~kJ} \mathrm{~mol}^{-1}
\end{array}
$$

and

$$
\mathrm{O}_{2}^{-}+\mathrm{H}_{2} \mathrm{O}_{2} \rightleftharpoons \mathrm{O}_{2}^{-}\left(\mathrm{H}_{2} \mathrm{O}_{2}\right)
$$

45 The Gibb's reaction energy given for (s2) has been modified from O'Sullivan's original value as outlined below. The $\Delta G_{r}^{o}$ value for (s3) compares favorably to that estimated using the linear correlation between ion-protonation energy and the Gibb's reaction energies for ion- $\mathrm{H}_{2} \mathrm{O}_{2}$ cluster formation (see main paper, $\Delta G_{r}^{o}=-94 \mathrm{~kJ} \mathrm{~mol}^{-1}$ ). The O'Sullivan et al. calculated $\Delta G_{r}^{o}$ s for ion-hydrates also agreed well (nominally within $7 \mathrm{~kJ} \mathrm{~mol}^{-1}$; sixth significant figure in the calculated Gibb's energy) with the NIST Chemistry WebBook tabulations. However, there was a large inconsistency between the Gibb's reaction energies for (s1) and (s2) and the $\Delta G_{f}^{o}$ for $\mathrm{O}_{2}^{-}\left(\mathrm{CH}_{3} \mathrm{OOH}\right)$ derived from their calculations using NIST or NIST derived reactant and product $\Delta G_{f}^{o}$ s from Table A6. The $\Delta G_{f}^{o}$ of $O_{2}^{-}\left(\mathrm{CH}_{3} \mathrm{OOH}\right)$ calculated from either (s1) or (s2) was expected to be within $7 \mathrm{~kJ} \mathrm{~mol}^{-1}$ but was found to be -340 or $-521 \mathrm{~kJ} \mathrm{~mol}^{-1}$, respectively, using O'Sullivan's original species specific Gibb's energies. The discrepancy was traced to a potential calculation issue for $\mathrm{O}_{2}^{-}\left(\mathrm{H}_{2} \mathrm{O}\right)$. The Gibb's energy for $\mathrm{O}_{2}^{-}\left(\mathrm{H}_{2} \mathrm{O}\right)$ was recalculated using the NIST Gibb's reaction energy for $\mathrm{O}_{2}^{-}+\mathrm{H}_{2} \mathrm{O} \rightleftharpoons \mathrm{O}_{2}^{-}\left(\mathrm{H}_{2} \mathrm{O}\right)$ (Table A6) and the O'Sullivan calculated Gibb's energies for $\mathrm{O}_{2}^{-}$and $\mathrm{H}_{2} \mathrm{O}$. Applying this hybrid Gibb's energy for $\mathrm{O}_{2}^{-}\left(\mathrm{H}_{2} \mathrm{O}\right)$ in (s2) rectified the $\Delta G_{f}^{o}$ of $\mathrm{O}_{2}^{-}\left(\mathrm{CH}_{3} \mathrm{OOH}\right)$ between (s1) and (s2). The resultant $\Delta G_{f}^{o}$ of $\mathrm{O}_{2}^{-}\left(\mathrm{CH}_{3} \mathrm{OOH}\right)$ was $-340 \mathrm{~kJ} \mathrm{~mol}^{-1}$ and the modified $\Delta G_{r}^{o}$ for reaction (s2) was $-181 \mathrm{~kJ} \mathrm{~mol}^{-1}$. These values are listed in Table A5 and Table A6, respectively.

A second issue exists between the derived NIST Gibb's formation energies and the O'Sullivan et al. (2017) Gibb's reaction energies for the formation of $\mathrm{O}_{2}^{-}\left(\mathrm{CO}_{2}\right)\left(\mathrm{H}_{2} \mathrm{O}_{2}\right)$. One pathway to $\mathrm{O}_{2}^{-}\left(\mathrm{CO}_{2}\right)\left(\mathrm{H}_{2} \mathrm{O}_{2}\right)$ formation is: 


$$
\mathrm{O}_{2}^{-}\left(\mathrm{CO}_{2}\right)+\mathrm{H}_{2} \mathrm{O}_{2} \rightleftharpoons \mathrm{O}_{2}^{-}\left(\mathrm{CO}_{2}\right)\left(\mathrm{H}_{2} \mathrm{O}_{2}\right) \quad \Delta G_{r}^{o}=-43 \mathrm{~kJ} \mathrm{~mol}^{-1}
$$

where the Gibb's reaction energy for (s4) is from O'Sullivan et al. A second pathway to $\mathrm{O}_{2}^{-}\left(\mathrm{CO}_{2}\right)\left(\mathrm{H}_{2} \mathrm{O}_{2}\right)$ is:

$$
\mathrm{O}_{2}^{-}\left(\mathrm{H}_{2} \mathrm{O}_{2}\right)+\mathrm{CO}_{2} \rightleftharpoons \mathrm{O}_{2}^{-}\left(\mathrm{CO}_{2}\right)\left(\mathrm{H}_{2} \mathrm{O}_{2}\right) \quad \Delta G_{r}^{o}=-85 \mathrm{~kJ} \mathrm{~mol}^{-1}
$$

and was proposed by us to reconcile the sensitivity trends observed in $\mathrm{O}_{2}^{-}\left(\mathrm{CO}_{2}\right)\left(\mathrm{H}_{2} \mathrm{O}_{2}\right)$ as a function of sample flow rate (sample pressure) and humidity. The O'Sullivan et al. calculated Gibb's reaction energy for (s5) is shown. The Gibb's reaction energies suggest both reactions would be spontaneous and the equilibrium constants would strongly favor the products. The Gibb's formation energy of $\mathrm{O}_{2}^{-}\left(\mathrm{CO}_{2}\right)\left(\mathrm{H}_{2} \mathrm{O}_{2}\right)$ was determined to be $-630 \mathrm{~kJ} \mathrm{~mol}^{-1}$ using the Gibb's formation energies for $\mathrm{O}_{2}^{-}\left(\mathrm{CO}_{2}\right)$ and $\mathrm{H}_{2} \mathrm{O}_{2}$ derived from NIST data and the O'Sullivan et al. Gibb's reaction energy for (s4).

Alternatively using the Gibb's formation energies for $\mathrm{O}_{2}^{-}\left(\mathrm{H}_{2} \mathrm{O}_{2}\right)$ and $\mathrm{CO}_{2}$ derived from NIST data and the Gibb's reaction energy for (s5), the Gibb's formation energy for $\mathrm{O}_{2}^{-}\left(\mathrm{CO}_{2}\right)\left(\mathrm{H}_{2} \mathrm{O}_{2}\right)$ would be $-721 \mathrm{~kJ} / \mathrm{mol}^{-1}$, a $-91 \mathrm{~kJ} \mathrm{~mol}^{-1}$ difference from that determined from (s4). At this point the reaction energies for (s4) and (s5) favored the production of $\mathrm{O}_{2}^{-}\left(\mathrm{CO}_{2}\right)\left(\mathrm{H}_{2} \mathrm{O}_{2}\right)$ by both reactions.

The Gibb's formation energies and Gibb's reaction energies for (s4) and (s5) were rectified similarly to the reconciliation of (s1) and (s2) thermodynamics above, but in so doing it reduces the argument for $\mathrm{O}_{2}^{-}\left(\mathrm{CO}_{2}\right)\left(\mathrm{H}_{2} \mathrm{O}_{2}\right)$ production by (s5). A key step in this reconciliation was a reanalysis of the energetics of $\mathrm{O}_{2}^{-}\left(\mathrm{CO}_{2}\right)$ production through reaction (s6)

$$
\mathrm{O}_{2}^{-}+\mathrm{CO}_{2} \rightleftharpoons \mathrm{O}_{2}^{-}\left(\mathrm{CO}_{2}\right) \quad \Delta G_{r}^{o}=-49 \mathrm{~kJ} \mathrm{~mol}^{-1}
$$

where, the reaction energy is derived from NIST data alone. The O'Sullivan et al. $a b$ initio calculated reaction energy for (s6) was $-141 \mathrm{~kJ} \mathrm{~mol}^{-1}$ or $92 \mathrm{~kJ} \mathrm{~mol}^{-1}$ lower than the NIST derived value. Ascribing the difference fully to the calculated Gibb's energy of $\mathrm{O}_{2}^{-}\left(\mathrm{CO}_{2}\right)$ in O'Sullivan's calculation, reducing this quantity by $91 \mathrm{~kJ} \mathrm{~mol}^{-1}$ while keeping the Gibb's reaction energies (s4) the same, necessitated reducing the calculated Gibb's energy for $\mathrm{O}_{2}^{-}\left(\mathrm{CO}_{2}\right)\left(\mathrm{H}_{2} \mathrm{O}_{2}\right)$ by the same amount. Propagating this change into the calculation of the Gibb's reaction energy for (s5), lead to $\Delta G_{r}^{o}=+7 \mathrm{~kJ} \mathrm{~mol}^{-1}$ for this reaction. Both (s4) and (s5) now yield the same Gibb's formation energy for $\mathrm{O}_{2}^{-}\left(\mathrm{CO}_{2}\right)\left(\mathrm{H}_{2} \mathrm{O}_{2}\right)$, which is equal to -630 $\mathrm{kJ} / \mathrm{mol}^{-1}$. The species Gibb's formation energies and the Gibb's reaction energies for (s4), (s5), and (s6) are thereby selfconsistent but at the expense of the calculated reaction energy for (s5) which is now positive and suggestive of a nonspontaneous reaction with an equilibrium constant slightly favoring the reactants. This only partially weakened the case for reaction ( $\mathrm{s} 5$ ) in the formation of $\mathrm{O}_{2}^{-}\left(\mathrm{CO}_{2}\right)\left(\mathrm{H}_{2} \mathrm{O}_{2}\right)$ because, while (s5) as revised is weakly endergonic, the reaction remains exothermic with an enthalpy of $\sim-20 \mathrm{~kJ} \mathrm{~mol}^{-1}$ as its expected reduction in entropy is of order $10^{2} \mathrm{~J} \mathrm{~mol}^{-1} \mathrm{~K}^{-1}$ based upon analogy with other hydroperoxide clustering reaction data (i.e., Böhringer et al., 1984; Messer et al. 2000; Cappa and Elrod, 2001).

S1.2 Modified kinetics data for the $\mathrm{O}_{2}^{-}-\mathrm{O}_{2}-\mathrm{CO}_{2}-\mathrm{H}_{2} \mathrm{O}$ - hydroperoxide system with $\mathrm{I}^{-}-\mathrm{H}_{2} \mathrm{O}-\mathrm{H}_{2} \mathrm{O}_{2}-$ HFo - HAC chemistry. 
After the ion-source tube, the reagent ion stream was assumed to instantaneously mix with ambient air. This air contains myriad other compounds most notably in terms of our reagent ion system: $\mathrm{H}_{2} \mathrm{O}, \mathrm{O}_{2}, \mathrm{CO}_{2}$ and $\mathrm{O}_{3}$. The model mechanism with respect to $\mathrm{O}_{2}^{-}$and its cluster ions with $\mathrm{H}_{2} \mathrm{O}$ and additional $\mathrm{CO}_{2}$ and $O_{2}$ follows Mohnen (1971), Kebarle et al. (1972), Fehsenfeld and Ferguson (1974) and Fahey et al. (1982). The full set of species considered and their reactions are listed in Tables A1 and A2, respectively. The species and reactions were developed in stages and the species and reaction indices (the number preceding the reaction) reflect that development. The main paper contains a list of reactions organized by the reacting ion.

Reagent ion hydration was critical. For the first hydrate, hydration can occur directly

$$
\mathrm{O}_{2}^{-}+\mathrm{H}_{2} \mathrm{O}+\mathrm{M} \rightarrow \mathrm{O}_{2}^{-}\left(\mathrm{H}_{2} \mathrm{O}\right)+\mathrm{M} \quad \mathrm{k}_{\mathrm{f}}=2.2 \times 10^{-28}\left(\mathrm{M}=\mathrm{O}_{2}\right)
$$

or indirectly through $\mathrm{O}_{2}^{-}\left(\mathrm{O}_{2}\right)$ and possibly $\mathrm{O}_{2}^{-}\left(\mathrm{CO}_{2}\right)$

$$
\begin{array}{ll}
\mathrm{O}_{2}^{-}+\mathrm{O}_{2}+M \rightarrow \mathrm{O}_{2}^{-}\left(\mathrm{O}_{2}\right)+M & \mathrm{kf}_{\mathrm{f}}=3-5 \times 10^{-31}\left(\mathrm{Ike} ; \mathrm{M}=\mathrm{O}_{2}\right) \\
\mathrm{O}_{2}^{-}\left(\mathrm{O}_{2}\right)+\mathrm{H}_{2} \mathrm{O} \rightarrow \mathrm{O}_{2}^{-}\left(\mathrm{H}_{2} \mathrm{O}\right)+\mathrm{O}_{2} & \mathrm{k}_{\mathrm{f}}=1.5 \times 10^{-9}(\mathrm{Ike}) \\
\mathrm{O}_{2}^{-}+\mathrm{CO}_{2}+M \rightarrow \mathrm{O}_{2}^{-}\left(\mathrm{CO}_{2}\right)+M & \mathrm{k}_{\mathrm{f}}=4.7 \times 10^{-29}\left(\mathrm{M}=\mathrm{O}_{2}\right) \\
\mathrm{O}_{2}^{-}\left(\mathrm{O}_{2}\right)+\mathrm{CO}_{2} \rightarrow \mathrm{O}_{2}^{-}\left(\mathrm{CO}_{2}\right)+\mathrm{O}_{2} & \mathrm{k}_{\mathrm{f}}=4.3 \times 10^{-10}(\mathrm{FFB}) \\
\mathrm{O}_{2}^{-}\left(\mathrm{CO}_{2}\right)+\mathrm{H}_{2} \mathrm{O} \rightarrow \mathrm{O}_{2}^{-}\left(\mathrm{H}_{2} \mathrm{O}\right)+\left(\mathrm{CO}_{2}\right) & \mathrm{kf}_{\mathrm{f}}<10^{-15} \text { (see discussion) }
\end{array}
$$

In these and subsequent reaction statements, $M$ denotes a third molecule and the references by: Ada = Adams et al. (1970); Alb = Albritton (1978); Ike = Ikezoe et al. (1986); Fah = Fahey et al. (1982); FF = Fehsenfeld and Ferguson (1974); FFB = Fehsenfeld et al. (1969); Hue = Huertas et al. (1978); PK = Payzant and Kebarle (1972); PP = Pack and Phelps (1966). The reaction rate coefficient for (13), $\mathrm{k}_{13}$, was set equal to $2.5 \times 10^{-10}$. This value of $\mathrm{k}_{13}$ was calculated assuming the switching reaction pair, (12) and (13),

$$
\text { a. } \mathrm{O}_{2}^{-}\left(\mathrm{H}_{2} \mathrm{O}\right)+\mathrm{CO}_{2} \rightleftharpoons \mathrm{O}_{2}^{-}\left(\mathrm{CO}_{2}\right)+\mathrm{H}_{2} \mathrm{O}=5.8 \times 10^{-10} \text { (Ada) }
$$

$$
\mathrm{K}_{\mathrm{eq}}=\mathrm{k}_{12} / \mathrm{k}_{13}=2.3(\mathrm{FF})
$$

could be combined to form a simple forward/reverse reaction sequence with the equilibrium constant equal to 2.3 (Fehsenfeld and Ferguson,1974).

\section{S1.3 Mono-carbonate and poly-hydrates.}

Payzant and Kebarle (1972) and Huertas et al. (1978) treated the formation of the second hydrate of $\mathrm{O}_{2}^{-}$as a termolecular reaction,

$$
\mathrm{O}_{2}^{-}\left(\mathrm{H}_{2} \mathrm{O}\right)+\mathrm{H}_{2} \mathrm{O}+\mathrm{M} \rightarrow \mathrm{O}_{2}^{-}\left(\mathrm{H}_{2} \mathrm{O}\right)_{2}+\mathrm{M} \quad \mathrm{k}_{\mathrm{f}}=5.4 \times 10^{-28}\left(\mathrm{M}=\mathrm{O}_{2}\right)
$$

whereas, Kazil (2002) treated this as a bimolecular reaction at pressures above some high-pressure threshold (unstated), $\mathrm{k}_{\mathrm{f}}=1.0 \times 10^{-9}$.

$$
\mathrm{O}_{2}^{-}\left(\mathrm{H}_{2} \mathrm{O}\right)_{2}+M \rightarrow \mathrm{O}_{2}^{-}\left(\mathrm{H}_{2} \mathrm{O}\right)+\mathrm{H}_{2} \mathrm{O}+\mathrm{M} \quad \mathrm{k}_{\mathrm{f}}=1.1 \times 10^{-14}(\mathrm{PK}, \mathrm{FF})
$$


Kebarle et al. (1972) and Fehsenfeld and Ferguson (1974) further suggest a sequence involving $\mathrm{O}_{2}^{-}\left(\mathrm{CO}_{2}\right)$ as a hydration path to $\mathrm{O}_{2}^{-}\left(\mathrm{H}_{2} \mathrm{O}\right)_{2}$ formation:

$$
\mathrm{O}_{2}^{-}\left(\mathrm{CO}_{2}\right)+\mathrm{H}_{2} \mathrm{O}+\mathrm{M} \rightarrow \mathrm{O}_{2}^{-}\left(\mathrm{CO}_{2}\right)\left(\mathrm{H}_{2} \mathrm{O}\right)+\mathrm{M} \quad \mathrm{kf}(\mathrm{est})=10^{-28} \text { (Hue) }
$$

followed by:

$$
\begin{array}{ll}
\mathrm{O}_{2}^{-}\left(\mathrm{CO}_{2}\right)\left(\mathrm{H}_{2} \mathrm{O}\right)+\mathrm{H}_{2} \mathrm{O} \rightarrow \mathrm{O}_{2}^{-}\left(\mathrm{H}_{2} \mathrm{O}\right)_{2}+\mathrm{CO}_{2} \quad \mathrm{k}_{148}(\mathrm{est})=1 \times 10^{-9}(\mathrm{Fah}) \\
\mathrm{k}_{148}(\mathrm{est})=1 \times 10^{-10} \text { (Hue) }
\end{array}
$$

especially, when $P\left(\mathrm{CO}_{2}\right)>P\left(\mathrm{H}_{2} \mathrm{O}\right)$ such as in the upper troposphere and above. Note, $\mathrm{k}_{148}$ presumed by Huertas et al. (1978) is an order of magnitude smaller than the assumed value used by Fahey et al. (1982) and is inconsistent with the reaction rate coefficient for reaction (147) measured by Fahey et al. and the equilibrium constants reported by Kebarle et al. (1972) and Fehsenfeld and Ferguson (1974). Kebarle et al. (1972) and Fehsenfeld and Ferguson (1974) gave equilibrium constants of 7 and 15, respectively, for the switching reaction pair (148) and (147),

$$
\mathrm{O}_{2}^{-}\left(\mathrm{H}_{2} \mathrm{O}\right)_{2}+\mathrm{CO}_{2} \rightarrow \mathrm{O}_{2}^{-}\left(\mathrm{CO}_{2}\right)\left(\mathrm{H}_{2} \mathrm{O}\right)+\mathrm{H}_{2} \mathrm{O} \quad \mathrm{k}_{147}=7 \times 10^{-11}(\mathrm{Fah})
$$

Further, the reaction products of (147) were not explicitly stated in Fahey et al. (1982) and those shown here were inferred from their discussion and the discussion of Mohnen (1972). The $\mathrm{O}_{2}^{-}\left(\mathrm{CO}_{2}\right)\left(\mathrm{H}_{2} \mathrm{O}\right)$ cluster generated in reaction (147) provides an alternative $\mathrm{O}_{2}^{-}\left(\mathrm{CO}_{2}\right)$ generating mechanism, (147) followed by (14):

$$
\mathrm{O}_{2}^{-}\left(\mathrm{CO}_{2}\right)\left(\mathrm{H}_{2} \mathrm{O}\right)+\mathrm{M} \rightarrow \mathrm{O}_{2}^{-}\left(\mathrm{CO}_{2}\right)+\mathrm{H}_{2} \mathrm{O}+\mathrm{M} \quad \mathrm{k}_{14}(\mathrm{est})=10^{-14} \text { (Hue) }
$$

Huertas et al. (1978) attributed his presumed reaction rate coefficient for (14) to Mohnen (1974). Reaction (14) combined with reaction (21) yields a simple equilibrium constant of $9 \times 10^{4}\left(\mathrm{~atm}^{-1} ; \mathrm{K}_{\mathrm{eq}}=\mathrm{k}_{21} / \mathrm{k}_{14}\right)$. The equilibrium constant for the combined equilibrium reactions $\mathrm{K}_{\mathrm{eq}}(12,13)$ and $\mathrm{K}_{\mathrm{eq}}(21,14)$ of $2.1 \times 10^{5}$ was within a factor of 5 of the NIST (2016) value for reaction (178)

$$
\begin{array}{r}
\mathrm{O}_{2}^{-}\left(\mathrm{H}_{2} \mathrm{O}\right)+\mathrm{CO}_{2}+\mathrm{M} \rightarrow \mathrm{O}_{2}^{-}\left(\mathrm{CO}_{2}\right)\left(\mathrm{H}_{2} \mathrm{O}\right)+M \quad \mathrm{Keq}_{\mathrm{eq}}=9.1 \times 10^{5}\left(\mathrm{~atm}^{-1}\right)(\mathrm{NIST})(178) \\
\mathrm{kf}_{\mathrm{f}}(\mathrm{est})=1 \times 10^{-28}(\mathrm{Hue}) \\
\mathrm{kr}_{\mathrm{r}}(\mathrm{est})=2.7 \times 10^{-15}=\mathrm{kf} / \mathrm{Keq}_{\mathrm{eq}}
\end{array}
$$

Kebarle et al. (1972) proposed reactions of the form:

$$
\mathrm{O}_{2}^{-}\left(\mathrm{H}_{2} \mathrm{O}\right)_{n>2}+\mathrm{CO}_{2} \rightarrow \mathrm{O}_{2}^{-}\left(\mathrm{CO}_{2}\right)\left(\mathrm{H}_{2} \mathrm{O}\right)_{n-1}+\mathrm{H}_{2} \mathrm{O}
$$

in their preliminary mechanism. Mohnen (1972) indicated these reactions were unlikely for $\mathrm{n}>3$ and Fahey et al. (1982) indicated these reactions are endothermic and slow for $\mathrm{n}>1$. There is some evidence for $\mathrm{O}_{2}^{-}\left(\mathrm{CO}_{2}\right)$ hydrates up to $n=2$ in Mohnen (1972) and reactions:

$$
\mathrm{O}_{2}^{-}\left(\mathrm{CO}_{2}\right)\left(\mathrm{H}_{2} \mathrm{O}\right)+\mathrm{H}_{2} \mathrm{O}+\mathrm{M} \rightarrow \mathrm{O}_{2}^{-}\left(\mathrm{CO}_{2}\right)\left(\mathrm{H}_{2} \mathrm{O}\right)_{2}+\mathrm{M}
$$

and

$$
\mathrm{O}_{2}^{-}\left(\mathrm{CO}_{2}\right)\left(\mathrm{H}_{2} \mathrm{O}\right)_{2}+\mathrm{M} \rightarrow \mathrm{O}_{2}^{-}\left(\mathrm{CO}_{2}\right)\left(\mathrm{H}_{2} \mathrm{O}\right)+\mathrm{H}_{2} \mathrm{O}+\mathrm{M}
$$

were included in our mechanism. Mohnen (1971) and Kebarle et al. (1972) included these reactions in their $\mathrm{O}_{2}^{-}, \mathrm{CO}_{2}$, and $\mathrm{H}_{2} \mathrm{O}$ mechanisms and Kebarle et al. gave a measured reaction enthalpy. In one of the $\mathrm{O}_{2}^{-}, \mathrm{CO}_{2}$, and $\mathrm{H}_{2} \mathrm{O}$ drift-tube 
experiments of Mohnen (1972), Mohnen called out strong signals attributed to $\mathrm{O}_{2}^{-}\left(\mathrm{CO}_{2}\right)$ and $\mathrm{O}_{2}^{-}\left(\mathrm{CO}_{2}\right)\left(\mathrm{H}_{2} \mathrm{O}\right)$ and weaker signals attributed to $\mathrm{O}_{2}^{-}\left(\mathrm{H}_{2} \mathrm{O}\right)_{n=4-7}$. While not specifically mentioned, weaker signals were also present in his data figure at masses of 50, 68, 86 and 112, which correspond to $\mathrm{O}_{2}^{-}\left(\mathrm{H}_{2} \mathrm{O}\right)_{n=1-3}$ and $\mathrm{O}_{2}^{-}\left(\mathrm{CO}_{2}\right)\left(\mathrm{H}_{2} \mathrm{O}\right)_{2}$, respectively. Huertas et al. (1976) included the reaction pair, (180) and (181), in their mechanism following Kebarle et al. and assumed the reaction rate coefficients were $1 \times 10^{-28}$ and $1 \times 10^{-13}$, respectively. The latter value for k181 was stated to be from Mohnen (1974), which in turn refers to Mohnen $(1971 ; 1972)$ but was not explicitly found within these three references. Here, we have included only the first and second order hydrates of $\mathrm{O}_{2}^{-}\left(\mathrm{CO}_{2}\right)$ in our model scheme. Higher order $\mathrm{O}_{2}^{-}$hydrates (up to n=5) are included (see reactions $70,71,192,193,194$, and 195) as they comprise a significant fraction of $O_{2}^{-}$at higher ambient and laboratory humidities.

The sensitivity trends in ion-hydroperoxide chemistry were difficult to reproduce and additional reaction schemes were employed. First it was thought the problem lay within reaction rate coefficients for reactions (12), (13), (14), (21), (24), 70 (147), and (148) describing the $\mathrm{O}_{2}^{-}-\left(\mathrm{H}_{2} \mathrm{O}\right)-\left(\mathrm{CO}_{2}\right)$ switching system as outlined below. Next, ozone, $\mathrm{O}_{3}$, present in the sample air could alter PCIMS hydroperoxide sensitivity as $O_{3}$ reacts with $O_{2}^{-}$reducing the $O_{2}^{-}$concentration and producing $\mathrm{O}_{3}^{-}$and $\mathrm{CO}_{3}^{-}$ions. Reactions capturing this chemistry were included. Also, a slower rate of reaction for (13) was required. Through systematic adjustment, we found $\mathrm{k}_{13}$ needed to be at or below $10^{-12}$ to leave sufficient $\mathrm{O}_{2}^{-}, \mathrm{O}_{2}^{-}\left(\mathrm{H}_{2} \mathrm{O}\right)$ and $\mathrm{O}_{2}^{-}\left(\mathrm{CO}_{2}\right)$ to fit our sensitivity data. This was approximately two orders of magnitude lower than predicted by the reaction (12)-(13) equilibrium. The following supported a potentially lower reaction rate coefficient for (13):

1) Banic and Iribarne (1985) argue $\mathrm{O}_{2}^{-}\left(\mathrm{CO}_{2}\right)$ is a "very stable" ion cluster in the troposphere and assumed it to be covalently bonded based upon Fehsenfeld and Ferguson (1974). In Fehsenfeld and Ferguson (1974) a covalently bonded $\mathrm{O}_{2}^{-}\left(\mathrm{CO}_{2}\right)$ cluster is not explicitly discussed although covalent bonding is discussed by them with respect to $\mathrm{HO}^{-}+\mathrm{SO}_{2}$ and $\mathrm{Cl}^{-}+\mathrm{SO}_{2}$ cluster reactions. They did, however, discuss reaction (13) indirectly, implying it was "slow". We infer this "slowness" is what lead to Banic and Iribarne's suggestion of covalent bonding in the $\mathrm{O}_{2}^{-}\left(\mathrm{CO}_{2}\right)$ cluster ion, as stronger covalent bonding would be expected in a slowly reacting cluster ion such as (13).

2) Hiraoka and Yamabe (1992) discuss evidence of covalent bonding in the $\mathrm{O}_{2}^{-}\left(\mathrm{CO}_{2}\right)$ ion because of a noted jump in cluster reaction enthalpy for the addition of additional $\mathrm{CO}_{2}$ to $\mathrm{O}_{2}^{-}\left(\mathrm{CO}_{2}\right)$ as compared to the reaction enthalpy changes noted with the addition of $\mathrm{CO}_{2}$ to $\mathrm{CO}_{3}^{-}$and $\mathrm{NO}_{2}^{-}$ions. This was interpreted as an indication of covalent bonding in $\mathrm{O}_{2}^{-}\left(\mathrm{CO}_{2}\right)$.

3) Hayhurst et al. (1992) show $\mathrm{O}_{2}^{-}\left(\mathrm{CO}_{2}\right)$ to increase in dry or wet air "rich" in $\mathrm{CO}_{2}(>100 \mathrm{ppm}$, and in keeping with our system) with a maximum in dry $\mathrm{CO}_{2}$ rich air but to virtually disappear in wet air "deficient" in $\mathrm{CO}_{2}(<2 \mathrm{ppm})$. 
4) Fehsenfeld and Ferguson further stated hydrated $\mathrm{O}_{2}^{-}\left(\mathrm{CO}_{2}\right)$ [i.e., $\mathrm{O}_{2}^{-}\left(\mathrm{CO}_{2}\right)\left(\mathrm{H}_{2} \mathrm{O}\right)$ ] reacts with $\mathrm{H}_{2} \mathrm{O}$ eliminating $\mathrm{CO}_{2}$ thereby making $\mathrm{O}_{2}^{-}\left(\mathrm{H}_{2} \mathrm{O}\right)_{2}$. In turn $\mathrm{O}_{2}^{-}\left(\mathrm{H}_{2} \mathrm{O}\right)_{2}$ can undergo dehydration to $\mathrm{O}_{2}^{-}\left(\mathrm{H}_{2} \mathrm{O}\right)$. Thus, the reaction sequence:

$$
\begin{array}{ll}
\mathrm{O}_{2}^{-}\left(\mathrm{CO}_{2}\right)+\mathrm{H}_{2} \mathrm{O}+\mathrm{M} \rightarrow \mathrm{O}_{2}^{-}\left(\mathrm{CO}_{2}\right)\left(\mathrm{H}_{2} \mathrm{O}\right)+M & \mathrm{k}_{21}<1 \times 10^{-30}(\mathrm{est}) \\
\mathrm{O}_{2}^{-}\left(\mathrm{CO}_{2}\right)\left(\mathrm{H}_{2} \mathrm{O}\right)+\mathrm{H}_{2} \mathrm{O} \rightarrow \mathrm{O}_{2}^{-}\left(\mathrm{H}_{2} \mathrm{O}\right)_{2}+\mathrm{CO}_{2} & \mathrm{k}_{148}(\mathrm{est})=1 \times 10^{-9}(\mathrm{Fah}) \\
& \multicolumn{1}{c}{\mathrm{k}_{148}(\mathrm{est})=1 \times 10^{-10} \text { (Hue) }} \\
\mathrm{O}_{2}^{-}\left(\mathrm{H}_{2} \mathrm{O}\right)_{2}+\mathrm{M} \rightarrow \mathrm{O}_{2}^{-}\left(\mathrm{H}_{2} \mathrm{O}\right)+\mathrm{H}_{2} \mathrm{O}+\mathrm{M} & \mathrm{k}_{51}=1.1 \times 10^{-14}(\mathrm{PK}, \mathrm{FF})
\end{array}
$$

results in a reaction sequence with products identical to those in (13).

5) O'Sullivan et al. (2017) simulated the bonding in $\mathrm{O}_{2}^{-}\left(\mathrm{CO}_{2}\right)$ using an ab initio method and suggested it is an adduct with weak covalent bonding.

6) Last, the value shown for $\mathrm{k}_{21}$ fits our $\mathrm{O}_{2}^{-}\left(\mathrm{CO}_{2}\right)\left(\mathrm{H}_{2} \mathrm{O}_{2}\right)$ sensitivity trend with water vapor much better than the reaction rate coefficient of $1 \times 10^{-28}$ estimated by Huertas et al. (1978) and subsequently cited by others (e.g., Popov, 2010). Mohnen (1971) also estimated a value of $1 \times 10^{-29}$ and which was smaller than that in Huertas.

We hypothesize a reaction sequence like (21), (148) and (51) together with (12) could give rise to a steady-state system in which a reaction like (13) appears in the net but occurs slowly if at all directly.

Reactions or reaction sequences represented by (149) - (152)

$$
\begin{array}{ll}
\mathrm{O}_{2}^{-}\left(\mathrm{H}_{2} \mathrm{O}\right)_{2}+\mathrm{H}_{2} \mathrm{O}_{2} \rightarrow \mathrm{O}_{2}^{-}\left(\mathrm{H}_{2} \mathrm{O}_{2}\right)+2 \mathrm{H}_{2} \mathrm{O} & \mathrm{k}_{149}=5.0 \times 10^{-10} \text { (est) } \\
\mathrm{O}_{2}^{-}\left(\mathrm{H}_{2} \mathrm{O}\right)_{3}+\mathrm{H}_{2} \mathrm{O}_{2} \rightarrow \mathrm{O}_{2}^{-}\left(\mathrm{H}_{2} \mathrm{O}_{2}\right)+3 \mathrm{H}_{2} \mathrm{O} & \mathrm{k}_{150}=2.5 \times 10^{-10} \text { (est) } \\
\mathrm{O}_{2}^{-}\left(\mathrm{H}_{2} \mathrm{O}\right)_{2}+\mathrm{CH}_{3} \mathrm{OOH} \rightarrow \mathrm{O}_{2}^{-}\left(\mathrm{CH}_{3} \mathrm{OOH}\right)+2 \mathrm{H}_{2} \mathrm{O} & \mathrm{k}_{151}=1.0 \times 10^{-10} \text { (est) } \\
\mathrm{O}_{2}^{-}\left(\mathrm{H}_{2} \mathrm{O}\right)_{3}+\mathrm{CH}_{3} \mathrm{OOH} \rightarrow \mathrm{O}_{2}^{-}\left(\mathrm{CH}_{3} \mathrm{OOH}\right)+3 \mathrm{H}_{2} \mathrm{O} & \mathrm{k}_{152}=5.0 \times 10^{-12} \text { (est) }
\end{array}
$$

followed by (160) and (161):

$$
\begin{array}{ll}
\mathrm{O}_{2}^{-}\left(\mathrm{CO}_{2}\right)+\mathrm{H}_{2} \mathrm{O}_{2} \rightarrow \mathrm{O}_{2}^{-}\left(\mathrm{H}_{2} \mathrm{O}_{2}\right)+\mathrm{CO}_{2} & \mathrm{k}_{160}=6.0 \times 10^{-10}(\text { est }) \\
\mathrm{O}_{2}^{-}\left(\mathrm{CO}_{2}\right)+\mathrm{CH}_{3} \mathrm{OOH} \rightarrow \mathrm{O}_{2}^{-}\left(\mathrm{CH}_{3} \mathrm{OOH}\right)+\mathrm{CO}_{2} & \left.\mathrm{k}_{161}=4.0 \times 10^{-10} \text { (est }\right)
\end{array}
$$

were added to the mechanism. Their inclusion improved the pressure dependent sensitivity and water vapor trends for the $\mathrm{O}_{2}^{-}$hydroperoxide clusters but did not significantly improve the pressure and water vapor sensitivity trends in $\mathrm{O}_{2}^{-}\left(\mathrm{CO}_{2}\right)\left(\mathrm{H}_{2} \mathrm{O}_{2}\right)$.

Next ozone effects on the chemistry were included. $O_{3}$ present in the sample air could alter the peroxide chemical ionization mass spectrometer (PCIMS) hydroperoxide sensitivity as $O_{3}$ reacts with $O_{2}^{-}$reducing the $O_{2}^{-}$concentration and producing $\mathrm{O}_{3}^{-}$and $\mathrm{CO}_{3}^{-}$ions:

$$
\begin{aligned}
& \mathrm{O}_{2}^{-}+\mathrm{O}_{3} \rightarrow \mathrm{O}_{3}^{-}+\mathrm{O}_{2} \\
& \mathrm{O}_{3}^{-}+\mathrm{CO}_{2} \rightarrow \mathrm{CO}_{3}^{-}+\mathrm{O}_{2}
\end{aligned}
$$


Additionally, $\mathrm{O}_{3}$ reacts with $\mathrm{O}_{2}^{-}\left(\mathrm{CO}_{2}\right)$ and $\mathrm{O}_{2}^{-}$hydrate clusters:

$$
\begin{aligned}
& \mathrm{O}_{2}^{-}\left(\mathrm{CO}_{2}\right)+\mathrm{O}_{3} \rightarrow \mathrm{O}_{3}^{-}+\mathrm{CO}_{2}+\mathrm{O}_{2} \\
& \mathrm{O}_{2}^{-}\left(\mathrm{H}_{2} \mathrm{O}\right)+\mathrm{O}_{3} \rightarrow \mathrm{O}_{3}^{-}+\mathrm{H}_{2} \mathrm{O}+\mathrm{O}_{2} \\
& \mathrm{O}_{2}^{-}\left(\mathrm{H}_{2} \mathrm{O}\right)_{2}+\mathrm{O}_{3} \rightarrow \mathrm{O}_{3}^{-}\left(\mathrm{H}_{2} \mathrm{O}\right)+\mathrm{H}_{2} \mathrm{O}+\mathrm{O}_{2} \\
& \mathrm{O}_{2}^{-}\left(\mathrm{H}_{2} \mathrm{O}\right)_{3}+\mathrm{O}_{3} \rightarrow \mathrm{O}_{3}^{-}\left(\mathrm{H}_{2} \mathrm{O}\right)_{2}+\mathrm{H}_{2} \mathrm{O}+\mathrm{O}_{2}
\end{aligned}
$$

to produce additional $\mathrm{O}_{3}^{-}, \mathrm{CO}_{3}^{-}$and their hydrates. The $\mathrm{O}_{3}$ reaction rate coefficients were assigned the same value regardless of the extent of $\mathrm{O}_{2}^{-}$hydration and carbonation in keeping with Fahey et al. (1982) who pointed out the addition of $\mathrm{CO}_{2}$ or $\mathrm{H}_{2} \mathrm{O}$ did not significantly reduce the reaction rate coefficient between $\mathrm{O}_{2}^{-}$or its cluster ions with $\mathrm{O}_{3} . \mathrm{O}_{3}$ has the potential to shift the ion population from $\mathrm{O}_{2}^{-}, \mathrm{O}_{2}^{-}\left(\mathrm{H}_{2} \mathrm{O}\right)_{n}$ and $\mathrm{O}_{2}^{-}\left(\mathrm{CO}_{2}\right)_{m}$ to $\mathrm{O}_{3}^{-}$and $\mathrm{CO}_{3}^{-}$.

\section{S1.4 Iodide}

Iyer et al. (2016) using ab initio methods estimated reaction rate coefficients and binding energies for $I^{-}$with $H F o$ and $H A C$. They also calculated binding energies for $\mathrm{I}^{-}$reactions with $\mathrm{H}_{2} \mathrm{O}_{2}$ and $\mathrm{CH}_{3} \mathrm{OOH}$ using the same methodology (Iyer, Pers. Comm., 2016). The respective binding energies for $\mathrm{I}^{-}(\mathrm{HFo}), \mathrm{I}^{-}(\mathrm{HAc}), \mathrm{I}^{-}\left(\mathrm{H}_{2} \mathrm{O}_{2}\right)$, and $\mathrm{I}^{-}\left(\mathrm{CH}_{3} \mathrm{OOH}\right)$ are 100, 73, 70, and

$60 \mathrm{~kJ} \mathrm{~mol}^{-1}$. Iyer et al. predicted sensitivities for many organic compounds based on the correlation of their calculated binding energies and the experimental sensitivities for organic acids published in Lee et al. (2014) for a CIMS TOF $I^{-}$ instrument. We have normalized their predicted sensitivities to $I^{-}(H F o)$ and the relative sensitivities are 1.000, 0.034, 0.007, and 0.001 for $\mathrm{I}^{-}(\mathrm{HFO}), \mathrm{I}^{-}(\mathrm{HAc}), \mathrm{I}^{-}\left(\mathrm{H}_{2} \mathrm{O}_{2}\right)$, and $\mathrm{I}^{-}\left(\mathrm{CH}_{3} \mathrm{OOH}\right)$, respectively. This ranking is consistent with the observations of O'Sullivan et al. (2017) in which they noted observing $\mathrm{I}^{-}\left(\mathrm{H}_{2} \mathrm{O}_{2}\right)$ but not $\mathrm{I}^{-}\left(\mathrm{CH}_{3} \mathrm{OOH}\right)$ clusters with the PCIMS instrument and with Treadaway et al. (2017) in which they observed a weak standard addition calibration signal for $\mathrm{I}^{-}\left(\mathrm{CH}_{3} \mathrm{OOH}\right)$ in the laboratory and during FRAPPE (Treadaway et al., 2017; Fig. 3). Fig. 8-10 (main paper) showed the sensitivity for $\mathrm{I}^{-}\left(\mathrm{H}_{2} \mathrm{O}_{2}\right), \mathrm{I}^{-}(\mathrm{HFO})$, and $\mathrm{I}^{-}(\mathrm{HAc})$ as a function of water vapor. The sensitivity of $\mathrm{I}^{-}\left(\mathrm{CH}_{3} \mathrm{OOH}\right)$ appeared to be independent of water vapor from the laboratory work, although the FRAPPE field calibrations suggested (Treadaway et al. 2017; Fig. 4) the sensitivity may increase with water like $\mathrm{I}^{-}(\mathrm{HFo})$ whereas, $\mathrm{I}^{-}\left(\mathrm{H}_{2} \mathrm{O}_{2}\right)$ and $\mathrm{I}^{-}(\mathrm{HAc})$ decrease over the limited range in humidity encountered in FRAPPE. 


\section{S2. References}

Adams, N. G., Bohme, D. K. , Dunkin, D. B., Fehsenfeld, F. C. , and Ferguson, E. E. :Flowing afterglow studies of formation and reactions of cluster ions of $\mathrm{O}_{2}^{+}, \mathrm{O}_{2}^{-}$, and $\mathrm{O}^{-}$, J. Chem. Phys., 52, 3133-3140, doi: 10.1063/1.1673449, 1970.

Albritton, D. L., : Ion-neutral reaction-rate constants measured in flow reactors through 1977, Atom. Data Nucl. Data Tables, 22, 1-101, 1978.

55 Banic, C. M. and Iribarne, J. V.: Equilibrium constants for clustering of neutral molecules about gaseous ions, J. Chem. Phys., 83, 6432-6448, doi: 10.1063/1.449543, 1985.

Bartmess, J. E.: "Negative Ion Energetics Data" in NIST Chemistry WebBook, NIST Standard Reference Database Number 69, Eds. P. J. Linstrom and W. G. Mallard, National Institute of Standards and Technology, Gaithersburg MD, 20899, http://webbook.nist.gov, retrieved August 19, 2016.

Böhringer, H., Fahey, D. W., Fehsenfeld, F. C., and Ferguson, E. E.: Bond energies of the molecules $\mathrm{H}_{2} \mathrm{O}, \mathrm{SO}_{2}, \mathrm{H}_{2} \mathrm{O}_{2}$, and $\mathrm{HCl}$ to various atmospheric negative ions, J. Chem. Phys., 81, 2805-2810, doi: 10.1063/1.447953, 1984.

65 Cappa, C. D. and Elrod, M. J.; A computational investigation of the electron affinity of $\mathrm{CO}_{3}$ and thethermodynamic feasibility of $\mathrm{CO}_{3}^{-}\left(\mathrm{H}_{2} \mathrm{O}\right)+\mathrm{ROOH}$ reactions, Phys. Chem. Chem. Phys., 3, 2986-2994, doi: 10.1039/b102981a, 2001.

Fahey, D.W., Böhringer, H., Fehsenfeld, F.C., and Ferguson, E.E.: Reaction rate constants for $\mathrm{O}_{2}^{-}\left(\mathrm{H}_{2} \mathrm{O}\right)_{\mathrm{n}}$ ions $\mathrm{n}=0$ to 4 , with $\mathrm{O}_{3}, \mathrm{NO}, \mathrm{SO}_{2}$, and $\mathrm{CO}_{2}$, J. Phys. Chem., 76, 1799-1805, doi: 10.1063/1.443220, 1982.

Fehsenfeld, F. C., Ferguson, E. E., and Bohme, D. K.: Additional flowing afterglow measurements of negative ion reactions of D-region interest, Planet. Space Sci., 17, 1759-1762, 1969.

Fehsenfeld, F. C. and Ferguson, E. E.: Laboratory studies of negative ion reactions with atmospheric trace constituents, 3181-3193, doi: 10.1063/1.1682474, 1974.

Goldsmith, C.F., Magoon, G. R., and Green, W. H.: Database of small molecule thermochemistry for combustion, J. Phys. Chem. A, 116, 9033-9057, 2012.

80 Hayhurst, C. J., Watts, P., and Wilders, A.: Studies on gas-phase negative ion/molecule reactions of relevance to ion mobility spectrometry: mass analysis and ion identification of the negative reactant ion peak in "clean" air, Intl. J. Mass Spect. Ion Proc., 121, 127-139, 1992.

Hiraoka, K. and Yamabe, S.: Formation of the chelate bonds in the cluster $\mathrm{O}_{2}^{-}\left(\mathrm{CO}_{2}\right)_{\mathrm{n}}, \mathrm{CO}_{3}^{-}\left(\mathrm{CO}_{2}\right)_{\mathrm{n}}$, and $\mathrm{NO}_{2}^{-}\left(\mathrm{CO}_{2}\right)_{\mathrm{n}}, \mathrm{J}$. Chem. Phys., 97, 643-650, doi:10.1063/1.463560, 1992.

Huertas, M. L., Fontan, J., Gonzalez, J.: Evolution times of tropospheric negative ions, Atmos. Environ., 12, 2351-2362, 1978.

90 Ikezoe, Y., Matsuoka, S., Takebe, M., and Viggiano, A.A.: Gas phase ion-molecule reaction rate constants through 1986, Ion Reaction Research Group of The Mass Spectroscopy Society of Japan, Tokyo, 1987.

Iyer, S., Lopez-Hilfiker, F., Lee, B. H., Thornton, J. A., and Kurtén, T.: Modeling the detection of organic and inorganic compounds using iodide-based chemical ionization, J. Phys. Chem. A, 120, 576-587, doi: 10.1021/acs.jpca.5b09837, 2016. 
Kazil, J.: The University of Bern atmospheric ion model: time-dependent ion modeling in the stratosphere, mesosphere and lower thermosphere, Ph.D. Thesis, University of Bern, Bern, Switzerland, 2002.

Kebarle, P., French, M., and Payzant, J. D.: Reaction mechanisms and bonding energies for ion-hydrates (ion-water clusters) of ionospheric interest, in: Aeronomy Report No. 48, COSPAR Symposium on D- and E-Region Ion Chemistry - An Informal Record, Eds. C. F. Sechrist, Jr., and M.A. Geller, University of Illinois at Urbana-Champaign, Urbana, IL, 1972.

Lee, B. H., Lopez-Hilfiker, F. D., Mohr, C., Kurtén, T., Worsnop, D. R., andThornton, J. A.: An iodide-adduct highresolution time-of-flight chemical-ionization mass spectrometer: application to atmospheric inorganic and organic compounds, Environ. Sci. Tech., 48, 6309-6317, doi: 10.1021/es500362a, 2014.

Messer, B. M., Stielstra, D. E., Cappa, C. D., Scholtens, K. W., and Elrod, M. J.: Computational and experimental studies of chemical ionization mass spectrometric detection techniques for atmospherically relevant peroxides, Intl. J. Mass Spect., 197, 219-235, 2000.

Mohnen, V.A.: Discussion of the formation of major positive and negative ions up to the $50 \mathrm{~km}$ level, P. Appl. Geophys., 84 , 141-151, 1971.

Mohnen, V. A.: Negative ions in air-like gas mixtures, P. Appl. Geophys., 100, 123-132, 1972.

Mohnen, V. A.: Formation, nature, and mobility of ions of atmospheric importance, $5^{\text {th }}$ Intl. Conf. on Atmos. Elect., Garmisch Partenkirchen, Germany, 2-7 September, 1974.

Ochterski, J. W.: Thermochemistry in Gaussian, help@gaussian.com, http://gaussian.com/thermo/, pdf file downloaded: 5 December 2012.

O'Sullivan, D. W., Silwal, I. K. C., McNeill, A. S., Treadaway, V., and Heikes, B. G.: Quantification of gas phase hydrogen peroxide and methyl hydroperoxide in ambient air: Using atmospheric pressure chemical ionization mass spectrometry with $\mathrm{O}_{2}^{-}, \mathrm{O}_{2}^{-}\left(\mathrm{CO}_{2}\right)$ reagent ions, submitted to: Int'l. J. Mass Spectrom., 2017.

Pack, J. L. and Phelps, A. V.: Electron attachment and detachment II. Mixtures of $\mathrm{O}_{2}$ and $\mathrm{CO}_{2}$ and $\mathrm{O}_{2}$ and $\mathrm{H}_{2} \mathrm{O}$, J. Chem. Phys., 45, 4316-4329, 1966.

Payzant, J. D. and Kebarle, P.: Kinetics of reactions leading to $\mathrm{O}_{2}^{-}\left(\mathrm{H}_{2} \mathrm{O}\right)_{\mathrm{n}}$ in moist oxygen, J. Chem. Phys., 56, 3482, doi: 10.1063/1.1677723, 1972.

Popov, N. A.: Evolution of the negative ion composition in the afterglow of a streamer discharge in air, Plasma Physics Reports, 36, 812-818, 2010, translated from Fizika Plazmy, 36, 867-873, 2010.

35 Treadaway, V., Heikes, B.G., McNeill, A. S., Silwal, I. K. C., and O'Sullivan, D. W.: Measurement of formic acid, acetic acid, hydrogen peroxide, and methyl peroxide in air by chemical ionization mass spectroscopy: airborne method development, in prep. Atmos. Meas. Tech., 2017. 